\title{
National Dental Clinical Fellow Scheme now open for applications
}

$\mathrm{E}$ ngland's Chief Dental Officer, Sara Hurley, has initiated a first national Dental Clinical Fellow Scheme for $2018 / 19$. The scheme is to be an integral component of the successful Faculty of Medical Leadership and Management (FMLM) Clinical Fellowship programme. It has been established to 'fast track and support dentists who present with the clearest potential to develop as dentistry leaders of the future'. Applications for the 2018/19 scheme must be received online by 9 am on 3 April 2018.

\section{The scheme}

Aligning the Chief Dental Officer, England's Clinical Fellow scheme with the long established FMLM NHS England National Medical Director's (NMD) and Chief Pharmaceutical Officer's schemes will ensure a wider multiprofessional dynamic for Dental Fellows melded with the FMLM curriculum and expertise.

The NMD scheme is now in its seventh year and has seen over 150 alumni pass through it. The scheme has demonstrated extensive benefits to both the fellows and the partner organisations, including improved delivery and quality of service, and multi-disciplinary collaboration.

\section{Partner organisations}

The Office of the Chief Dental Officer has partnered with a number of invited prestigious organisations who will host and sponsor a full or part-time Clinical Fellow post, including Bupa, Health Education England (North West, in Manchester), the General Dental Council, the Faculty of Dental Surgery, NHS Business Services Authority (in Eastbourne), and NHS England in London and Leeds. By the end of the Fellowship the Dental Fellows should have had the opportunity to: understand how the healthcare system works from outside of clinical practice; work directly with senior leaders across a diverse range of organisations to develop their experience and skills in leadership, management, strategy, project management and health policy; and collaborate across organisations on projects to share knowledge, challenges and innovative ideas through a series of learning events and networking opportunities.

\section{Eligibility criteria}

The posts will commence on 1 September 2018 and run for 12 months. The scheme is open to dentists with a minimum of two years' post registration experience in clinical dentistry and at least two years' experience of delivering NHS services [the posts are not age related, however, and dentists may apply at any stage in their career]. Applicants must also be registered and in good standing with the GDC; be eligible to work in the UK; must not already hold an established/formal senior leadership role or a clinical speciality; be able to provide complete details of their employment history; and have evidence that their present level of achievement and performance is adequate and appropriate to take on a leadership role.

For further information and to apply, please visit: https://www.fmlm.ac.uk/ programmes-services/individualsupport/clinical-fellow-schemes/ chief-dental-officers-clinical-fellow-scheme.

\section{Case study}

The first four Dental Clinical Fellows in post for the 2017/18 period include Dr Nishma Sharma. Nishma is a mother of two, has been a dentist for 15 years and while she is a Dental Clinical Fellow at the Office of the Chief Dental Officer in London she also works in general practice three days a week in Hertfordshire alongside her role as a Clinical Advisor for NHSE Central and South Midlands.

Her role in the CDO Office is predominantly alongside Eric Rooney, Deputy CDO, and includes: Dental Contract Reform; Leading the Change (incorporating the development of this scheme and ensuring dentistry is incorporated into the New Models of Care); and Organisational Development of the LDNs within the OCDO.

Commenting on her experience,

Nishma said: 'Working in practice day to day I just wanted something more. I wanted to

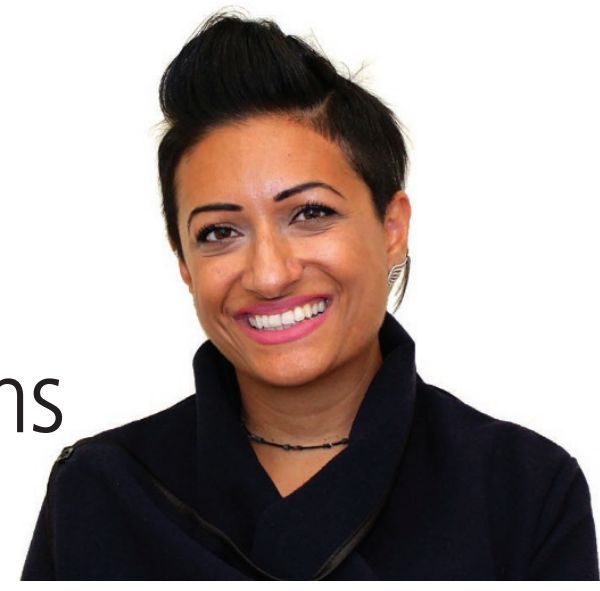

Nishma Sharma, current Dental Clinical Fellow

know who commissions services and by what method it is done; where policy is made and how it is created; as well as the details, like the difference between an LDN and an LDC.

'This scheme has been the single most unpredictable, rewarding, and influential career move I have ever made. Every day is different, and I now have a new found respect for leadership and what it is to be a leader. I am proud to have discovered qualities I never knew I had, and even more proud to enhance those qualities in my time on the scheme. The impact it has made on both a personal and professional level is surprisingly profound; I cannot recommend this scheme enough.

'The way our medical and pharmaceutical colleagues are able to work so closely together in their field to develop strong clinical leaders of the future and ensure they have a seat at the table is nothing short of inspirational and aspirational. For so long they have had the edge over leadership and development schemes and they seem to have excelled at putting together collaborative network pathways and positions most coveted by early career medics. The calibre of Fellows I have the pleasure of working alongside this year is nothing short of exceptional. Being able to approach senior members of the dental world, explain the significance of what we are trying to pull together with the backing of the Office, asking them to participate in something new and unheard of in our field and them having the insight and faith in us - potential new leaders - to commit to helping be a part of this initiative has been most humbling.

'I welcome any organisation that can help dentistry, dentists and dental professionals bridge this gap we have in the leadership and management arena. Having been involved with all aspects of this scheme from the start, I feel I can personally vouch for its credibility as a way for "normal" dentists with natural leadership talents to discover what they never knew they didn't know.' 